\title{
411
}

\section{Impact of Fishing Boat/Craft and Gear Combinations Operating in Coastal Fishery on Fisher Income in Sri Lanka}

\author{
Amaralal K.H.M.L., Wimalasena H.D. and Maheepala M.M.A.S. \\ National Aquatic Resources Research and Development Agency, \\ Mattakkuliya, Sri Lanka \\ *mmasmaheepala@yahoo.com
}

\begin{abstract}
Coastal fishery is an important sub-sector of the fisheries sector in the country. Coastal fish production in 2012 was $257,540 \mathrm{Mt}$ and its contribution to the total marine fish production was around $62 \%$. More than 100,000 fishers are engaged in the coastal fishery sub-sector who represent more than $50 \%$ of the fishers of the country. There are several types of fishing boats/crafts and gears are used in the coastal fishery. This study has been done to examine variation in the per fisher income by different craft and gear combinations used in the coastal fishery. The study was conducted in 2012 and the sampling frame confined to outboard fibre reinforced plastic boats (OFRP), outrigger canoes (Oru), log rafts (Teppam) and motorized traditional crafts (Wallam). The sample selection was done by application of random sampling and data collection carried out administering structured questionnaires. A total number of 150 of above mentioned fishing boats/crafts of five fishing districts in the Southern and West coast were subjected to this study. Two hypotheses were tested under this study: 1. There is no difference in per fisher income of different fishing crafts $(\mathrm{H} 0$ : $\mu 1=\mu 2=\mu 3=\mu 4) 2$. There is no difference in per fisher profit according to fishing gears (H0: $\mu 1=\mu 2=\mu 3=\mu 4)$. The collected data were analysed using SPSS software and considered $\alpha$ level was 0.05 for the test. Calculated $F$ value for the first hypothesis was $1.94(\mathrm{P}=0.107)$ which indicated that the Null hypothesis of the first test can't be rejected. It means the per fisher income does not change acoording to the fishing boats/crafts. The calculated $F$ value for the second hypothesis was $2.50(\mathrm{P}=0.009)$ which explained that the Null hyposthesis of the second hypothesis can be rejected. It means that the per fisher profit will be changed acoording to fishing gears used in the coastal fishery. According to the mean seperation it was proven that the fishers who use trawl lines and bottom long lines earned higher profits than the fishers who use other fishing gears.
\end{abstract}

Keywords: Coastal fishery, Fisher income, Fishing gear, Fishing boats 